\title{
Social routines and the consumption of food
}

\author{
Mark Tomlinson and Andrew McMeekin
}

In this chapter we argue that considerations of routine behaviour are essential in order to gain a realistic understanding of consumption. There are useful insights from the evolutionary accounts of decision making in firms that can be transferred to the realm of consumer behaviour. To augment the notion of routine that emerges from this literature, and specifically to explore what is social about routines, we also draw on sociological accounts of consumption that identify the extent to which tastes are shared among groups within society. This conceptualisation is reinforced by recourse to statistical analysis of real consumption data from Great Britain.

The notion of the social routine behaviour of individuals is important for scholars interested in studies of innovation, but has received little attention. After all, product innovation requires consumers to adapt or break their consumption routines. Therefore, understanding the nature of these routines is crucial for a complete understanding of innovation processes.

\section{The notion of routines in studies of organisations}

A routine is an executable capability for repeated performance in some context that [has] been learned by an organization in response to selective pressures. (Cohen et al., 1996, p. 683, emphasis in original)

In studies of organisations there has been a tradition of looking at routines as the basis for understanding organisational action (March and Simon, 1958; Cyert and March, 1963). In this tradition, routines arise out of a tendency to reduce continued deliberation in repetitive situations. When analysing business decision making, Nelson and Winter (1982) emphasise the role of social routines, which are at once partly inherited and partly adaptive. That is, the routine may be partly the result of learned behaviour, either within or outside a group, or partly a new response to a changing environment. Cohen and Bacdayan (1994) see organisational routines as patterned sequences of learned behaviour, involving multiple actors who are linked by relations of communication and/or authority. 
Thus many neo-Schumpeterian and evolutionary theorists have examined the nature of routines within organisations (especially firms), looking at the degree to which they are stable, the extent to which they change and the implications of these dynamics. In particular, the notion of routines has been used to understand apparent path dependence in the technological innovations that emerge from the firm.

The central motivation for studying routines comes from empirical observations of recurrent action, which do not easily fit into a neoclassical utility-maximising framework. Hodgson has written several papers that question the validity of theories of rational action stemming from the work of Milton Friedman. He argues that Friedman sidestepped issues of 'realistic analyses of the way in which business people decide and act. He disregarded empirical evidence of the routine-driven nature of business activity ...' (Hodgson, 1997, p. 663). Hodgson argues that analyses of decision making should consider the importance of habits and rules. Specifically, his interest lies in understanding the circumstances in which agents are required to exhibit habitual behaviour.

Old institutional economics saw habits as central to their understanding of institutions and human agency in general. Veblen (1898), for example, saw habits as essential to an understanding of behaviour. Habits were seen as non-reflective repeated patterns of activity that in some sense saved the individual from having to repeatedly 'rationally' calculate optimal decisions from a range of choices. Old institutional economics stands in sharp contrast to the utility-maximising theories of consumption that are central to mainstream neoclassical economics. Veblen also noted the tension between purposive action and habit as the defining characteristic of human beings. A more detailed account of the importance of habits in understanding the behaviour of agents can be found in Hodgson (1997, pp. 664 ff.).

The path-dependent nature of habitual action suggests that the actions of today are predicated on previous behaviour. There is an accumulation of knowledge related to the repetition of actions that leads to the strengthening of a particular habit. (Early psychologists, such as Hull, 1930, 1942, have explored how habit strength varies with the number of reinforcements.) Once an agent accumulates sufficient knowledge about a certain action, the action is performed without recourse to repeated reflection; this then becomes the habit. Linked with this notion of habitual action and of the concept of path-dependence, mentioned above, is the idea of learning-by-doing (Arrow, 1962) and learning-by-using (Rosenberg, 1982).

Here, it is important to draw a distinction between the notion of habit and that of routine. Habitual behaviour relates to the unreflective repeated action of individuals, whereas routine behaviour is about the same phenomenon but at the level of the group. In other words, routines refer to the shared patterns of behaviour within a group context and involve interaction between various agents. For evolutionary accounts of technological change, these routines 
can refer to the staff of a particular firm, or to members of a particular scientific discipline.

We again find resonance here with the old institutional economics. Regarding the relationship between institutions and habits, Hodgson (n.d., p. 3) suggests that: 'Particular habits spread through society, leading to the emergence or reinforcement of institutions; and institutions foster and underline particular habits and transmit them to new members of the group.'

While this range of conceptualisations of routine and habitual behaviour may appear to be in agreement, there is a very important difference in the frameworks that have been proposed. The agreement is that there is a tendency to reduce deliberation and calculation in repetitive situations. The differences are in the explanations of why this may be the case.

For some, the primary explanation of routine behaviour lies in the cognitive constraints on the potential to repeatedly calculate an optimal course of action. These accounts include the psychological treatments of habit and the economists' notion of bounded rationality and are usually explored by considering only the individual human agent. Other accounts stress the organisational dimension of routine behaviour, where social contexts are responsible for reinforcing repetitive action. Furthermore, the learning and adaptation that lead to modifications in routines or indeed the breaking of routines also occur within a social context.

This distinction is far from trivial, and is at the core of this chapter. We argue that routines are often governed by social contexts and test this notion by examining social consumption routines. To further elaborate this aspect of consumption routines, and to develop a framework for identifying the existence of groups of consumers that exhibit broadly similar consumption behaviour, we turn to the sociology literature.

\section{Bourdieuvian sociology of consumption}

In sociological accounts of consumption, there has also been vociferous debate regarding the extent to which consumption behaviour is shared within social groups. One of the central propositions of the 'postmodernist' approach to understanding consumption is that the importance of socio-structural context has decreased over time; we now live in a time where traditional forms of social stratification (for instance, along class, gender or racial lines) are less important than the individual's ability to calculate individual actions rationally and where new forms of social structure create 'new' post-traditional social groups with quite different attitudes and orientations. Hence there is a burgeoning literature on different lifestyles, Green movements, 'queer' studies, etc.

On the other hand, and defending a more 'structuralist' position, there is a continuing body of work that takes a more traditional collectivist stance as a starting point, many of them drawing on the work of Bourdieu. Bourdieu often uses the concept of 'habitus' to help to explain the behaviour of different social groups, particularly their consumption patterns. In his classic 
work Distinction (1984) he takes this concept and builds a framework within sociology that seeks to understand how consumers may act in different (social) situations. The habitus can be thought of as a general set of rules and dispositions defining the behaviour of a socially constituted group. For Bourdieu, the groups are usually delineated by occupational classes. Different social groups or classes have different habituses, depending on several factors which can lead to variations in levels of education, income, social capital, and so on.

The habitus is the medium through which actions (including consumption) are mediated in everyday life: what governs the acceptable and unacceptable for the group. Habitus is to some extent passed on from one generation to the next, partly modified by education, and subject to various changes dependent on the life course an individual finds himself/herself undertaking (whether by accident or design). This concept has resonance with the notions of habit in old institutional economics, but should not be confused with habit itself. The habitus is more than just a set of habits.

The similarities in the general ideas are quite striking. For instance, Veblen (1898, p. 79) stated that: '[Man's] methods of life today are enforced upon him by his habits of life carried over from yesterday and the circumstances left as the mechanical residue of the life of yesterday.' In other words, there are inculcated habits and beliefs that shape the desires of people that are not always easy to break free from. Compare this with Bourdieu's (1984, p. 172.) discussion of the habitus and lifestyle:

Life-styles are ... the systematic products of habitus, which, perceived in their
mutual relations through the schemes of the habitus, become sign systems which
are socially qualified. ... The dialectic of conditions and habitus is the basis of
an alchemy which transforms the distribution of capital, the balance sheet of a
power relation, into a system of perceived differences, distinctive properties,
that is, a distribution of symbolic capital, legitimate capital, whose objective
truth is misrecognised.

Bourdieu (1984, p. 101) reduces social practices to the following 'equation':

$$
\{\text { (habitus) (capital) }\}+\text { field }=\text { practice }
$$

What this implies is that an agent's behaviour is governed by a combination of three factors: the habitus itself, the levels of economic, social and cultural capital the individual is endowed with (this is the general level of wealth, knowledge, culture and education possessed by the agent), and the field that the agent is operating in. The field can modify the habitus to some extent. Field is a notoriously difficult concept to define, but can be thought of as a more general area of life that is to some extent independent of any class-oriented habitus. So someone working in the field of education may have different behavioural patterns from someone working in the field of the arts despite having similar levels of cultural capital and occupational status. 
The mode of operation of the social routine can be readily incorporated within the habitus framework. The type of framework put forward by Bourdieu can also help to explain apparently sub-optimal or irrational behaviour, as it supplies alternative logics to social consumption and the objects of consumption habits that are absent from mainstream economic analysis (which relies mainly on prices and incomes). For example, 'Objects, even industrial products, are not objective in the ordinary sense of the word, i.e. independent of the interests and tastes of those who perceive them, and they do not impose the self-evidence of a universal, unanimously approved meaning' (Bourdieu, 1984, p. 100).

Objects of consumption therefore are not objective in the sense that the social possibilities available to the consumer are not the same for different social groups.

The sociologists of consumption can therefore shed useful light on the processes that govern the dynamics of routines and in particular the relationship between an individual's actions and the behaviours of social groups. Economists have recently started to deploy some of these ideas in empirical and simulation work on consumption (for example, see McMeekin and Tomlinson, 1998; Cowan et al., 1996). For example, Cowan et al. (1996, p. 7) state that:

In Bourdieu's analysis (1984), taste is driven in part by the desire for distinction and peer group reference, and that gives rise to an explicitly evolutionary character to consumption patterns. But this last theory lacks the power of a quantitative modelling framework which an evolutionary economic theory of consumption can bring.

The social mechanisms referred to here, of aspiration, association and distinction, are key features of Bourdieu's sociology of consumption.

The preceding discussion leads us to formulate an initial definition of social 'consumption routines' based on the original definition of organisational routines:

A consumption routine is an executable capability for repeated consumption that has been learned or acquired by groups of consumers in response to social pressures or contexts.

It is this that we begin to operationalise in what follows by modelling the influence of social context on routine consumption behaviour.

\section{Data and methodology}

The data: the Health and Lifestyle Survey

The data were initially collected in 1984 and 1985 to form a random sample of 9,003 respondents aged eighteen or over and resident in households in Great Britain. The data collected included many variables related to the area of consumption and lifestyles. For example, detailed data on food consumption, smoking, alcohol consumption, hobbies, exercise, etc., as well as 
socio-demographic variables including social class, household composition, etc., were gathered. The interviewees were traced and re-interviewed seven years later (referred to as the 'follow-up survey') and the same questions were repeated. Thus we have similar data from two points in time for the same people. However, a number of respondents from the first wave could not be traced or had died. Thus the sample size of the follow-up survey is reduced from 9,003 to 5,352 .

\section{The influence of social class}

We have argued that factors such as social class will be significant determinants of habitual consumption behaviour, whereas traditional neoclassical economic analyses of consumption typically take income as the primary determinant. In this section we use real consumption data to show that in many cases, although income is important, social class is often a stronger determinant, as would be predicted by Bourdieu. We assume that social class represents the context in which tastes are formed and consumption routines executed. Moreover these contexts have a persistent effect which lasts even when the social class changes. Thus social mobility will affect tastes, but there will be a residual effect stemming from the consumer's origins (the habitus effect).

\section{Modelling consumption}

In most quantitative economic analyses of consumption the dependent variable is usually some measure of expenditure on a particular good. However, this data set does not have expenditure data. Rather, it has data on the frequency with which an item is consumed. The items covered include food, leisure activities, etc. So our dependent variable is an ordered categorical variable reflecting the strength of an individual's particular consumption routine. For example, whether an individual consumes red meat more than once a day, once a day, down to the category 'never' (there are usually six categories per item). We use consumption frequency in 1992 (i.e. the second wave) as our dependent variable and model the influence of various factors on this outcome. Also, because the categories are not equidistant, it would be unwise to rely on ordinary least squares regression techniques. We therefore use ordered logistic regressions, which do not assume that the categories are equidistant but retain the order of the categories. The independent variables included in the models are:

1 Social class in 1985. In the analysis that follows we use occupational class in 1985 as a proxy for habitus. We are assuming that if occupational class is statistically significant then this is a reflection of the underlying influence of habitus. This assumption is consistent with Bourdieu's own analysis. For the class variables, we have the basic Registrar General's (RG) class of the household head as well as the more detailed socio-economic group (SEG). We are concentrating on RG class below. The rationale for using RG class is that it is simpler and closely corresponds to the social class 
scheme used by advertisers in their marketing strategies (i.e. the familiar A, B, C1, C2, D, E grouping). The Registrar General's class is analogous and is defined as follows:

I Professionals

II Managers

IIIN Routine white-collar workers

IIIM Skilled manual workers

IV Semi skilled workers

V Unskilled workers

Whenever we refer to class in what follows this is the scheme that we are using. Class V, unskilled workers, is used as the base category. We use class in 1985 rather than 1992 as a reflection of the underlying, pathdependent disposition to consume certain items rather than others. This is a significant departure from most consumption models. We are basically arguing that long-standing dispositions have an effect on future consumption. Hence we predict consumption in 1992 on the basis of habitus effects stemming from 1985.

2 Mobility between 1985 and 1992. We assume that not only will there be latent habitus effects from original class position, but that these can be modified by shifts in occupational status. Thus people who move from blue to white-collar jobs, say, will modify their behaviour to be more 'white-collar' but will retain some of their old 'blue-collar' habits. (We use 'blue' and 'white' collar as a shorthand device. There may be occupations in the classes IIIM, IV and V that are not strictly manual jobs and hence not strictly 'blue-collar'.) This change in social context will induce 'learning' or 'adaptation' and hence modified behaviour, but there will be tastes which essentially persist from earlier social contexts. We construct two variables to represent this phenomenon. Firstly a dummy variable indicating whether the person shifted from class IIIM, IV or V into class I, II or IIIN (i.e. from a 'blue' to a 'white' collar occupation), and second a variable representing the opposite case. We resort to this simple scheme, as it would be too complex to have variables representing every possible type of occupational shift.

3 Age in 1992. We constructed age dummy variables dependent on whether a person is in his or her thirties, forties, fifties or sixty or over. The base category is people under thirty.

4 Gender. We entered a female dummy variable in the models; therefore males are the base categories.

5 Income in 1992. The base category is less than $£ 79$ net weekly income. The dummy variables are $£ 79-£ 173, £ 174-£ 288, £ 289+$ net weekly income.

So, schematically, we are modelling consumption routines in 1992 as in Figure 1. 


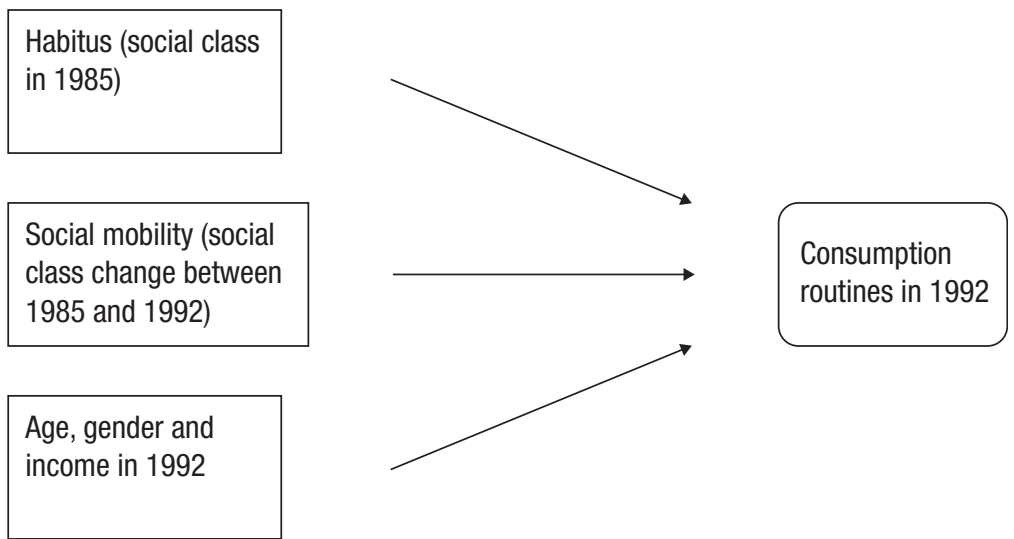

Figure 1 Modelling routine consumption

\section{Results}

If persistence in routine behaviour or changes in it were not in some ways determined by social context then we would find no significance for the habitus variable or for the mobility variable. In our models, for a number of goods analysed, we find that either the habitus variable or both the habitus and mobility variables were significant after controlling for income. This suggests, in a convincing manner, that the individualistic framework provides an insufficient explanation.

We are primarily interested in the social determinants of routine consumption behaviour, and the modelling results fall into three categories with respect to this. ${ }^{1}$

1 Consumption routines for goods that fall into this category are determined by both long-standing habitus effects (the 1985 class variable is significant) but not by social mobility (the white/blue-collar shift variables are significant). This suggests that the habitus effects persist and that social mobility makes no significant impact. We call this habitus-dominated routine consumption (see Figure 2).

2 Consumption routines for goods that fall into this category are determined by both long-standing habitus effects (the 1985 class variable is significant) and are also influenced by social mobility (the white/bluecollar shift variables are significant). In this case the routine consumption is influenced by persistent habitus effects and is also subject to adjustment from social mobility. We call this mobility-adjusted routine behaviour (see Figure 3).

3 Consumption routines for goods that fall into this category are not significantly determined by long-standing habitus effects (the 1985 class variable is insignificant) or social mobility (the white/blue-collar shift variables are significant). The consumption of these goods would appear to be less 
Habitus (social class in 1985)

Social mobility (social class change between 1985 and 1992)

Age, gender and income in 1992

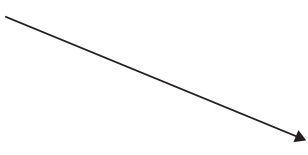

Consumption routines in 1992

Figure 2 Habitus-dominated routine

Habitus (social class in 1985)

Social mobility (social class change between 1985 and 1992)

Age, gender and income in 1992
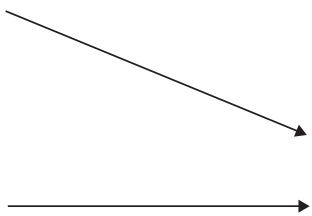

Consumption routines in 1992

Figure 3 Mobility-adjusted routine

influenced by differences in social context. We call this habitus-neutral routine consumption (see Figure 4).

The goods we examined fell into the three categories:

1 Habitus-dominated, class 1985 significant, mobility non-significant: yoghurt, salad, squash, cheese.

2 Mobility-adjusted, class 1985 significant, mobility significant: tea, coffee, pasta, chips, fruit juice.

3 Habitus-neutral, class 1985 non-significant, mobility non-significant: potatoes, sweets, pulses.

Examples of models of type 1, 2 and 3 goods are shown in Table 1.

Persistent habitus dispositions influence the routine consumption of yoghurt, salad, squash and cheese. The consumption of these goods does not 


Habitus (social class
in 1985)

Social mobility (social class change between 1985 and 1992)

Age, gender and income in 1992
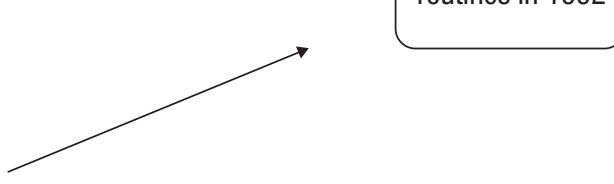

Figure 4 Habitus-neutral routine

Table 1 Examples of the three different types of model (ordered logistic regressions)

\begin{tabular}{|c|c|c|c|}
\hline \multirow[b]{3}{*}{ Independent variable } & \multicolumn{3}{|c|}{ Dependent variable } \\
\hline & Habitus-dominated & Mobility-adjusted & Socially neutral \\
\hline & Yoghurt & Fruit juice & Potatoes \\
\hline \multicolumn{4}{|l|}{ Class: } \\
\hline I & $0.77 * * *$ & $0.91 * * *$ & - \\
\hline II & $0.57 * * *$ & $0.94^{* * * *}$ & - \\
\hline IIIN & $0.55^{* * *}$ & $0.90 * * *$ & - \\
\hline IIIM & $0.34 * *$ & $0.49^{* * *}$ & - \\
\hline $\begin{array}{l}\text { IV } \\
\text { (Base: class V) }\end{array}$ & - & - & - \\
\hline Female & $0.37 * * *$ & $0.37 * * *$ & - \\
\hline \multicolumn{4}{|l|}{ Age: } \\
\hline Thirties & - & - & - \\
\hline Forties & $0.24 *$ & - & $0.51^{* * *}$ \\
\hline Fifties & $0.39 * * *$ & - & $1.05 * * *$ \\
\hline $\begin{array}{l}\text { Sixties and above } \\
\text { (Base: under thirty) }\end{array}$ & $0.57 * * *$ & $-0.28 * *$ & $1.36^{* * *}$ \\
\hline \multicolumn{4}{|l|}{ Income group: } \\
\hline 2 & $0.40 * * *$ & $0.39 * *$ & $0.26^{* * *}$ \\
\hline 3 & $0.53 * * *$ & $0.61 * * *$ & $0.27^{* * *}$ \\
\hline $\begin{array}{l}4 \\
\text { (Base: 1, lowest) }\end{array}$ & $0.59 * * *$ & $0.91 * * *$ & - \\
\hline White-collar shift & - & $0.27^{* *}$ & - \\
\hline Blue-collar shift & - & - & - \\
\hline
\end{tabular}

Notes Only significant coefficients on independent variables are shown. - Not significant at the $5 \%$ level. *Significant at the $5 \%$ level. **Significant at the $1 \%$ level. ***Significant at the $0.1 \%$ level. 
significantly alter when people change their occupational status. So, for example, white-collar workers in 1985 routinely consumed more yoghurt in 1992, whether they had occupational mobility or not. Those who only became white-collar workers between 1985 and 1992 are only as likely to consume as if they were still blue-collar workers. However, in the case of tea, coffee, pasta, chips (US: french fries) and fruit juice, consumers who had shifted to white-collar occupations were likely to shift their consumption behaviour in line with other white-collar workers. For these goods there appears to be an 'aspirational' or 'learning' effect, although the original class position remains significant.

These results are particularly interesting because they suggest that habitus and social mobility operate in different ways for different goods. This also raises the question of why goods should differ in this way. The consumption of potatoes depends significantly less on habitus than yoghurt; and while yoghurt consumption appears unaffected by mobility, both habitus and mobility determine pasta consumption.

\section{Conclusion}

Earlier, we offered the following definition of consumption routine:

A consumption routine is an executable capability for repeated consumption that has been learned or acquired by groups of consumers in response to social pressures or contexts.

The analysis in this chapter has concentrated on the social pressures or contexts that lead to the nature of consumption routines. There are several interesting findings.

First, we have shown that habitus can be a strong determinant of consumption routines. Modelling consumption by past social status is an unusual way to do this, and is probably an even stronger indication of its importance than simply using current social class. It suggests the longer-term persistence of habitus in appropriately defining the groups within which routines are shared.

Second, we have shown that social mobility can also have a significant effect on consumption routines. This resonates with our definition with respect to the notion of learning or adaptation. It suggests that consumers who have shifted from, say, blue-collar occupations to white-collar occupations will in some cases adapt their consumption behaviour accordingly. This they may do consciously, actively aspiring to behave in similar ways to their new colleagues, or through unconscious imitation. One implication is that shifts in the social structure will have an effect on aggregate consumption behaviour and the demand for goods.

Third, the effects of these influences are different depending on the good that is being examined. This is particularly interesting since it implies that goods differ with respect to the way they are perceived by different social groups; in other words some goods appear to carry more social significance 
than others. We have characterised three different types of goods. Type 3 (habitus-neutral) goods do not appear to have any significant social meaning within this framework, whereas type 1 (habitus-dominated) and type 2 (mobility-adjusted) do. But the social significance of these goods is different.

The existence of consumption routines is particularly significant for those interested in the diffusion of innovative consumer products. The implication is that existing routines need to be modified or broken for innovations to succeed. This is reflected in practice, as advertisers and market research functions attempt both to reinforce routine consumption behaviour and to break it. This they frequently do through activities that are based on stratified populations of consumers. Marketers are well known for using the A, B, C1, C2, D, E scheme (analogous to the scheme we have used here). Consequently product ranges are designed so that a hierarchy of products are offered to different social groups. Advertisements are also created and presented in such a manner as to make clear the social significance of consuming certain goods.

These conclusions lead to important suggestions for understanding the consumption of new product innovations. There is a tension between the learned and routine behaviour of groups of individuals with respect to frequently purchased and common items of consumption (such as nondurables) and the arrival of novel, new or unknown goods that may change behaviour in unexpected ways. This is acknowledged by Bourdieu (1984, pp. 230 ff.) and by Warde (1997), who discusses the antinomy of taste with respect to novelty and tradition in food consumption. This antinomy is the tension between the need for familiarity (governed by routine) and humanity's passion for novelty and innovation.

We have demonstrated that consumption routines can change for certain goods and at different rates for different social groups. Understanding consumption behaviour as governed by routines and social mechanisms is essential to understanding the evolution of demand.

\section{Note}

1 We do not discuss the importance of age, gender and income in this chapter, because we are concentrating on the question of socio-economic class and consumption routines. For a discussion of these issues see Tomlinson and McMeekin (1998).

\section{References}

Arrow, K. (1962), 'The economic implications of learning by doing', Review of Economic Studies, 29, pp. 155-73.

Bourdieu, P. (1984), Distinction: a social critique of the judgement of taste, London, Routledge.

Cohen, M., and Bacdayan, P. (1994), 'Organizational routines are stored as procedural memory: evidence from a laboratory study', Organization Science, 5 (4), pp. 554-68. 
Cohen, M. D., Burkhart, R., Dosi, G., Egidi, M., Marengo, L., Warglien, M., and Winter, S. (1996), 'Routines and other recurring action patterns of organizations: contemporary research issues', Industrial and Corporate Change, 5 (3), pp. 653-98.

Cowan, R., Cowan, W., and Swann, P. (1996), 'A Model of Demand with Interaction among Consumers', Research report 9609, London, Ont., Department of Economics, University of Western Ontario.

Cox, B. D. (1988), University of Cambridge School of Clinical Medicine, Health and Lifestyle Survey, 1984-85 (HALS 1) [computer file], Colchester, The Data Archive [distributor], 13 October 1988, SN: 2218.

Cox, B. D. (1995), University of Cambridge Department of Community Medicine, Health and Lifestyle Survey: seven-year follow-up, 1991-92 (HALS 2) [computer file], Colchester, The Data Archive [distributor], 30 January 1995, SN: 3279.

Cyert, R. M., and March, J. G. (1963), A Behavioural Theory of the Firm, Cambridge, Blackwell.

Hodgson, G. M. (n.d.), 'Notes on Habits, Institutions and Evolution', Judge Institute of Management Studies, University of Cambridge (mimeo).

Hodgson, G. M. (1997), 'The ubiquity of habits and rules', Cambridge Journal of Economics, 21, pp. 663-84.

Hull, C. (1930), 'Knowledge and purpose as habit mechanisms', Psychological Review, 37, pp. 511-25.

Hull, C. (1942), Principles of Behaviour: an introduction to behaviour theory, New York, Appleton-Century.

March, J. G., and Simon, H. (1958), Organizations, New York, Wiley.

McMeekin, A., and Tomlinson, M. (1998), 'Diffusion with distinction: the diffusion of household durables in the UK', Futures, 13 (9), pp. 873-86.

Nelson, R., and Winter, S. (1982), An Evolutionary Theory of Economic Change, Cambridge MA, Harvard University Press.

Rosenberg, N. (1982), Inside the Black Box: technology and economics, Cambridge, Cambridge University Press.

Tomlinson, M., and McMeekin, A. (1998), 'Does the "Social" have a role in the Evolution of Consumption?', CRIC Discussion Paper 14, Manchester, CRIC.

Veblen, T. B. (1898), 'Why is economics not an evolutionary science?' Quarterly Journal of Economics, 12 (3), pp. 373-97, reprinted in Veblen, T. B. (1919), The Place of Science in Modern Civilization, New York, Huebsch.

Warde, A. (1997), Consumption, Food and Taste: culinary antinomies and commodity culture, London, Sage. 